\title{
Article
}

\section{All UK electricity supplied by wind and photovoltaics - The 30-30 rule}

Fragaki, Aikaterini, Markvart, Tom and Laskos, Georgios

Available at http://clok.uclan.ac.uk/25635/

Fragaki, Aikaterini ORCID: 0000-0003-1754-9617, Markvart, Tom and Laskos, Georgios (2019) All UK electricity supplied by wind and photovoltaics - The 30-30 rule. Energy, 169 . pp. 228-237. ISSN 0360-5442

It is advisable to refer to the publisher's version if you intend to cite from the work. http://dx.doi.org/10.1016/j.energy.2018.11.151

For more information about UCLan's research in this area go to http://www.uclan.ac.uk/researchgroups/ and search for < name of research Group>.

For information about Research generally at UCLan please go to http://www.uclan.ac.uk/research/

All outputs in CLoK are protected by Intellectual Property Rights law, including Copyright law. Copyright, IPR and Moral Rights for the works on this site are retained by the individual authors and/or other copyright owners. Terms and conditions for use of this material are defined in the policies page.

\section{CLoK}

Central Lancashire online Knowledge www.clok.uclan.ac.uk

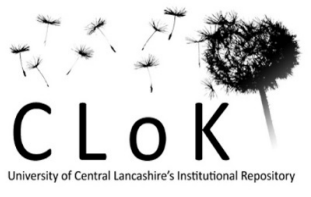




\title{
All UK electricity supplied by wind and photovoltaics - the $30-30$ rule
}

\section{Author information}

Aikaterini Fragaki*

School of Engineering, University of Central Lancashire, Preston PR1 2HE, UK,

*Corresponding author, e-mail: afragaki@uclan.ac.uk, Tel:004401772893826

Tom Markvart ${ }^{1,2}$

${ }^{1}$ Solar Energy Laboratory, Faculty of Engineering and the Environment, University of

Southampton, Southampton SO17 1BJ, UK,

${ }^{2}$ Centre for Advanced Photovoltaics, Czech Technical University, 16636 Prague 6, Czech

Republic

Georgios Laskos

Solar Energy Laboratory, Faculty of Engineering and the Environment, University of

Southampton, Southampton SO17 1BJ, UK,

\begin{abstract}
Based on weather and electricity demand data for the period 1984 - 2013, we develop a system model based on energy balance to determine the size of photovoltaic and wind generation combined with energy storage to provide a firm power supply for Great Britain. A simple graphical methodology is proposed where the required wind and PV generation capacities can be read off from a "system configuration diagram" as a function of the available storage size. We show, by way of illustration, that a reliable supply would be produced by a system based on PV and wind generators generating some 30\% more electrical energy (approximately 100 TWh p.a.) than the current electricity supply system if supplemented with 30 days of storage. In terms of generation capacities, the current $82 \mathrm{GW}$ of principally thermal generation would then be replaced by about $150 \mathrm{GW}$ of wind turbines and $35 \mathrm{GW}$ of $\mathrm{PV}$ arrays.
\end{abstract}

Keywords: Wind; Photovoltaics; Electricity demand; UK; Energy storage;

\section{Introduction}

In response to climate change agreements starting from Rio in 1992 to Paris in 2016, there is a steady drive to replace fossil fuels with low-carbon energy sources. For example, the UK government - alongside a number of other countries - has pledged to reduce carbon emission by $80 \%$ below 1990 levels by $2050^{1}$. This will undoubtedly mean electrification of most of the user sectors with the use of, in a large part, renewable sources. In the case of UK, a significant part is likely to come from wind, with possibly a smaller component of solar photovoltaics, creating the challenge of replacing a large amount of dispatchable power stations with intermittent generation. 
Possible solutions that have been suggested to meet this challenge include extending and strengthening the high voltage transmission system with links to neighbouring power systems (for example, strengthening the existing links to France, the Netherlands and Ireland, and building a new link to Norway), demand side management, sustainable biomass and energy storage ${ }^{[2,3,4]}$. Even though substantial uncertainties exist it is likely that any future system will include elements of these technologies. In this paper we consider a simplified model where the intermittent nature of wind and photovoltaic (PV) generators is balanced only by energy storage. We shall show that, despite this restricted scenario, the model provides useful information about the size of storage and additional generation capacity that might be needed, as well as informing the policy makers about the role of demand management and the amount of sustainable fuel such as biomass that might be needed. Interconnection to other power systems can serve as an alternative solution, to be investigated in a separate publication.

This paper uses historic weather and electricity demand data ${ }^{5,6}$ for the past 30 years to find the minimum generation and the minimum size of energy storage to provide power without interruption during this 30 year period of analysis. The methodology is based on energy balance where, in a similar way to the design of stand-alone wind and photovoltaic systems ${ }^{7}$, the key features are determined by variations in weather on the scale of days rather than hours. In contrast with recent research based on hourly simulations, ${ }^{[2,3,4]}$ the significant simplification that this affords allows us to display clearly the principal characteristics of system operation over the entire 30 year period of analysis. The model is easily generalised to a situation where the intermittent generators are combined with a flat (for example, nuclear) generation, supplying a constant baseload.

Whilst no attempt is made to predict the future electricity demand, the analysis is constructed around a realistic variation of the demand during the year based on historic data, assuming the total annual demand is kept constant. This makes it possible to determine the required size of energy storage (in energy units) and the required wind and solar generation power capacities in relation to this total annual electricity demand. Only on-shore wind production is considered, due to the availability of wind speed data over a prolonged period of time ${ }^{8}$ and the difficulties and potential errors in the determination of power generation in atmospheric marine conditions, making it difficult to capture the necessary statistics of the resource which are key to the prediction of the size of energy storage needed. When appropriate data are available the analysis can be expanded without difficulty in the future to include also offshore wind production.

\section{Energy generation and demand}

The precise location of future wind farms and solar arrays cannot be predicted with any certainty but the sites are likely to be distributed across positions with good wind and solar resource. This philosophy was followed in this study whilst ensuring a relatively even spread over regional representation of sites with high wind or high solar resource across Great Britain (Fig. 1). 
The wind turbines and solar arrays were positioned at each generation site in such a way that each site generates the same amount of energy over the 30 year period of analysis. For example, the sizes of PV arrays at Camborne, Aberporth, Sutton Bonington and East Malling are such that each location produces the same amount of energy over the 30 years from 1984 to 2013. As a typical scenario we have placed wind turbines and PV arrays near the locations of the respective resource measurement station (Sec. 2). For wind energy generation, only sites with wind speeds above $5 \mathrm{~ms}^{-1}$ at $10 \mathrm{~m}$ anemometer height were considered in this work
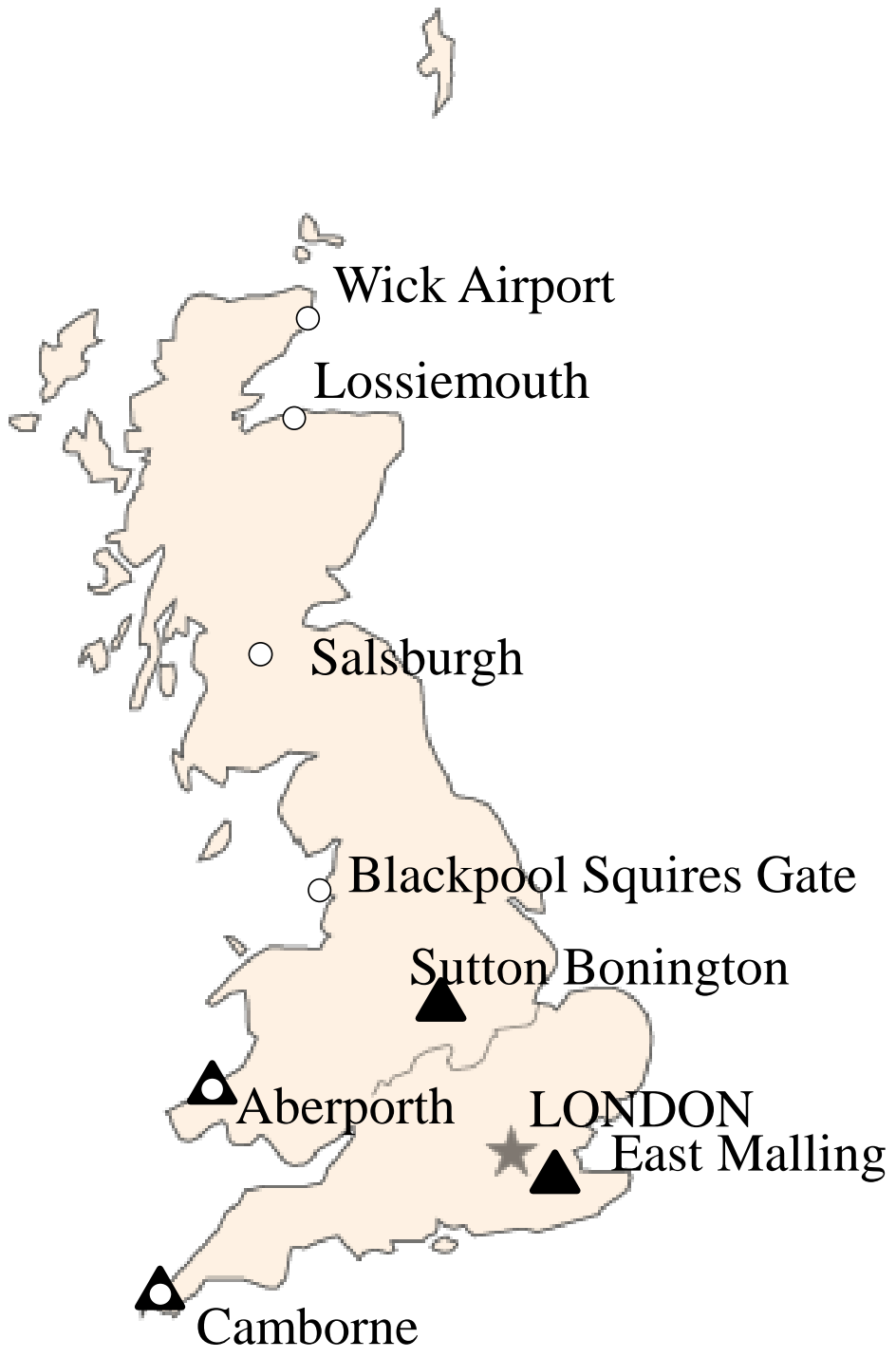

Fig. 1. Location of wind (triangles) and solar (circles) generators considered in this study.

Long term (1984-2013, half hourly) data are available only for the England and Wales power system. This is also the area typically covered in related research ${ }^{9}$. Reliable Scottish electricity data are only available since 2005. Since E\&W and GB have similar day-to-day load patterns between 2006 and 2013 (relative difference in daily electricity demand between the two profiles ranging from $2.0 \%$ to $3.3 \%$, with $\mathrm{E} \& \mathrm{~W}$ contributing between $90 \%$ to $91 \%$ of the total GB annual electricity) an accurate estimate of the time profile of GB during the 30 year period can be obtained by scaling the $\mathrm{E} \& \mathrm{~W}$ demand by a factor of 1.1 . 
The daily load values were adjusted by adding or subtracting a constant load, different for each year, to yield a daily load profile with equal annual total for each year. This yields a similar load profile for each year (Fig. 2), with slight differences from year to year depending on climatic and economic conditions, the timing of public holidays etc.

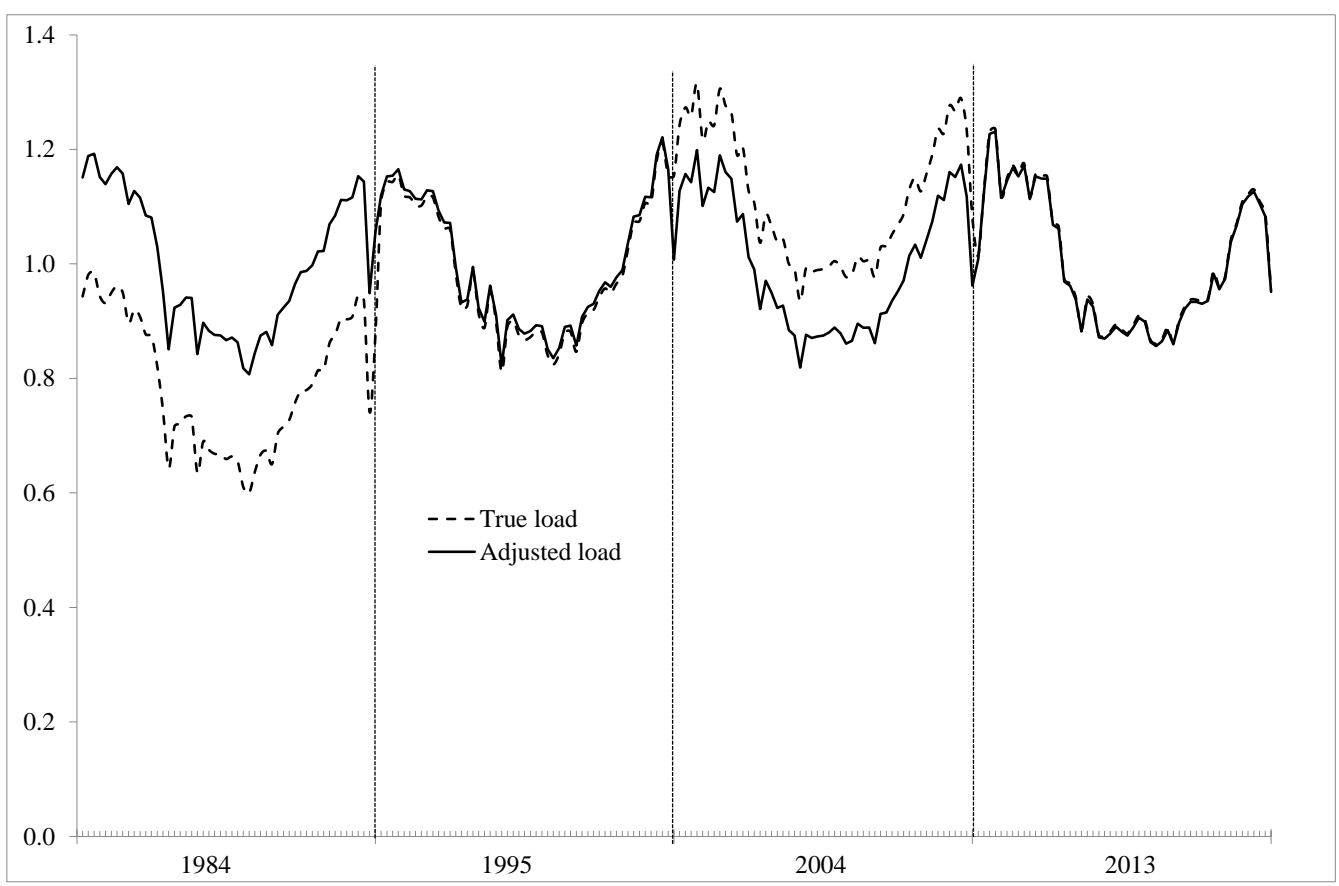

Fig 2 True and adjusted load profiles to remove the year to year variation.; Example shows years 1984, 1995, 2004 and 2013

To capture the variation of the electricity demand throughout the year (which may be different from year to year) rather than predict the evolution of this demand into the future we have normalised the total annual demand to a constant value and, in the final discussion, expressed the required generation and storage relative to this value. The results, therefore, reflect a realistic demand profile throughout the year but the total demand can be adjusted according to detailed predictions from separate studies. By the same token, the results can be used to estimate the required storage and wind and solar capacities in the presence of a constant source of power such as nuclear.

Using the measured wind speed data the energy production by a wind turbine has been determined by a standard procedure ${ }^{9,10}$ based on a widely used wind turbine ${ }^{11}$ that is the IEC 2.5 MW Nordex N90/2500 LS/HS. This selection is in accordance with the findings from studies on future wind turbine characteristics ${ }^{12}$, which suggest that the rated power and the diameters of wind turbines will level off between 2020 and 2030. 
The energy produced by a wind turbine is typically estimated using the manufacturer's data and wind speed data at the site. The wind speed was extrapolated to turbine hub height using the $\log$ law, ${ }^{13}$ assuming surface roughness $0.03 \mathrm{~m}$ for all sites ${ }^{10}$. This value of surface roughness is for an open farmland terrain with few trees and buildings ${ }^{14}$ - the terrain type most representative of the sites where weather stations are typically located.

It is common practice ${ }^{9}$ to assume that the wind speed is constant during each hour. The power produced each hour is then a function of the wind speed for this hour, and can be estimated from the power curve of the turbine.

To determine the total wind energy generation for Great Britain at the system level, the output from an individual wind turbine was scaled to include losses within the wind farm and due to wind energy curtailments, to obtain an average long-term load factor in keeping with the reported values for on shore wind for the UK and for Scotland. ${ }^{15}, 16$.

$$
\bar{l}_{w}=<l_{w j}>=0.28
$$

where $l_{w j}$ denotes the load factor for wind generation in year $j$. Based on the measured daily solar radiation data, the energy production by solar arrays was determined in a standard manner ${ }^{7,17}$. We have used the optimum for what is essentially a hybrid system operating in the South of England, with south facing arrays at a tilt angle of $30^{\circ}$. The system losses incurred in operation away from standard test conditions were allowed for with the use of a Performance Ratio $0.84^{18}$, giving a long-term load factor for photovoltaic generation

$$
\bar{l}_{s}=<l_{s j}>=0.116
$$

where $l_{s j}$ denotes the load factor for solar generation in year $j$. The different load factors between wind and photovoltaic generation indicate that, in Great Britain, wind turbines generate approximately 2.42 times more energy for the same amount of generation capacities installed. This also implies that larger total installed capacity does not necessarily mean an increase in the energy produced.

\section{System configurations to provide firm capacity}

A convenient starting point to discuss the required size of energy storage and the capacities of wind and solar generators is to consider the minimum generation capacities that would produce just enough energy to cover the load over the 30 year design period.

The total wind and solar generator capacities $P_{s}$ and $P_{w}$, normalised to a dimensionless form using the average power $L / T=34.9 \mathrm{GW}$, where $L$ is the total energy consumed as load over the 30-year design period and $T=10,958$ days is the duration of the 30 year design period

$$
\overline{P_{S}}=\frac{P_{S} T}{L} ; \overline{P_{w}}=\frac{P_{w} T}{L}
$$

clearly have to satisfy

$$
\bar{l}_{s} \bar{P}_{s}+\bar{l}_{w} \overline{P_{w}} \geq 1
$$


System configurations corresponding to equation (2) can be displayed graphically in the $\bar{P}_{S}-$ $\overline{P_{w}}$ configuration plane, bounded by a straight line defined by the equality sign that defines the minimum generation capacities (Fig. 3). It is also useful to define the total energy generated relative to the load $f_{g}$ that compares the energy generated to the load over the 30-year design period.

$$
\boldsymbol{f}_{\boldsymbol{g}}=\frac{\sum_{k=1}^{T} E(\boldsymbol{k})}{L} \quad, \quad f_{g} \geq 1
$$

where $E(k)$ is the energy production on day $k$

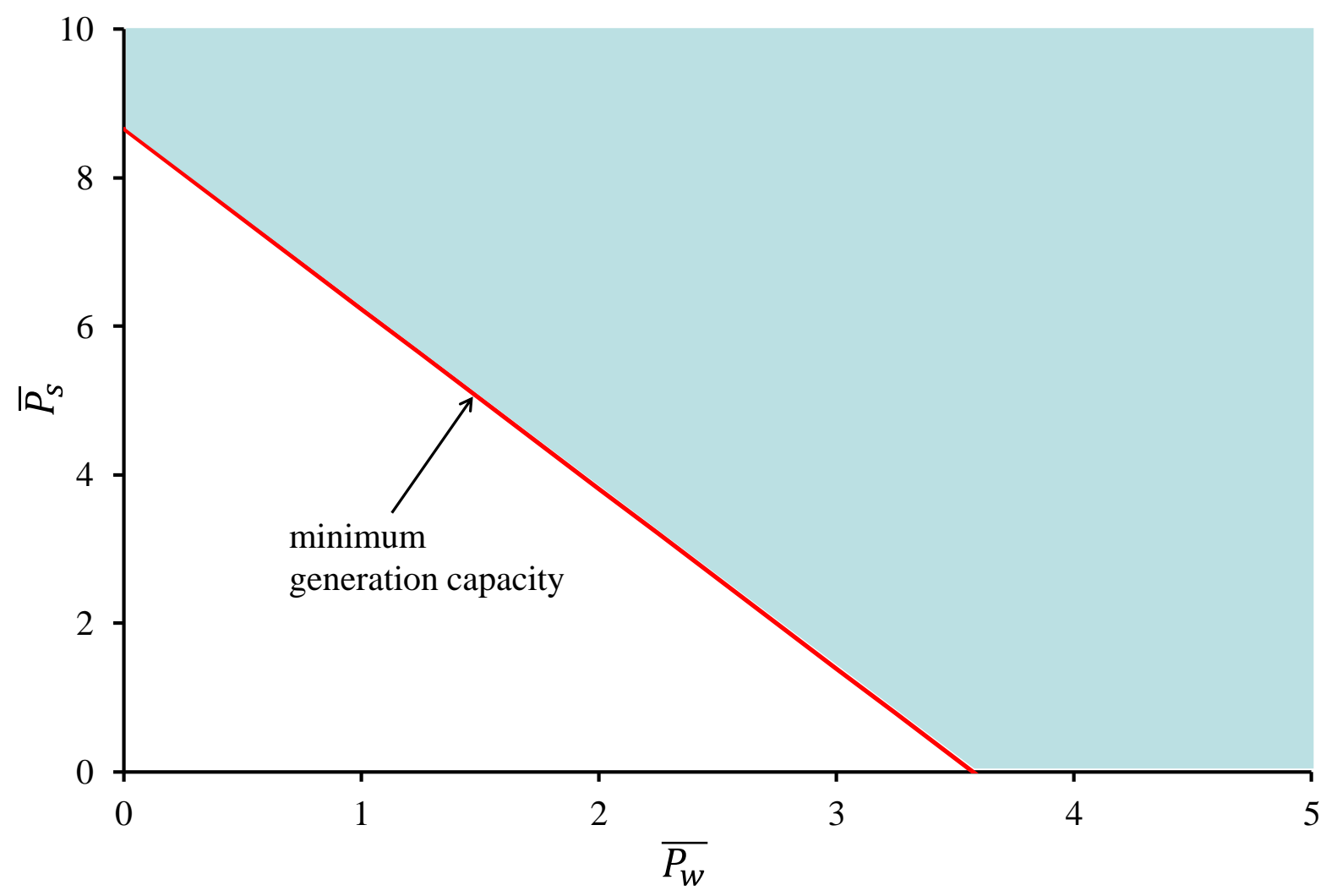

Fig. 3. The configuration plane of the normalised wind and solar generators $\overline{P_{w}}$ and $\bar{P}_{s}$ defining a region of permissible generation capacity.

We can now consider the size of energy storage corresponding to the minimum generation in equation (2), or, equivalently, to $f_{g}=1$, to take up any short-term mismatch between the energy generated on the one hand, and consumed by the load on the other. We seek to determine system configurations that would meet the load demand without interruption over the 30 years of the study, based on the weather data for the period $1984-2013$. This can readily be done with the use of a system model based on energy balance.

The energy store is needed to store energy over two distinct time scales. There is, on the one hand, the daily (night / day) mismatch between generation and load (which is usually fairly predictable) which requires energy storage of a size equal to a fraction of the daily load. An 
energy store of a much larger size, on the other hand, is needed to compensate for the mismatch between generation determined by actual weather patterns and the variable load which is expected to be of the order of the energy demand for several weeks, if not months. The daily mismatch represents therefore a small correction which can simply be added to the principal storage requirement based on longer term variation of the weather. This consideration allows a significant simplification of the system model which can be based on daily generation and demand rather than half- hourly or hourly energies as has been the usual practice in other works ${ }^{2,3,4}$ The key variable that provides the necessary information about energy storage is the energy deficit in the store as a function of time which can be determined using a simple algorithm shown in Fig. 4

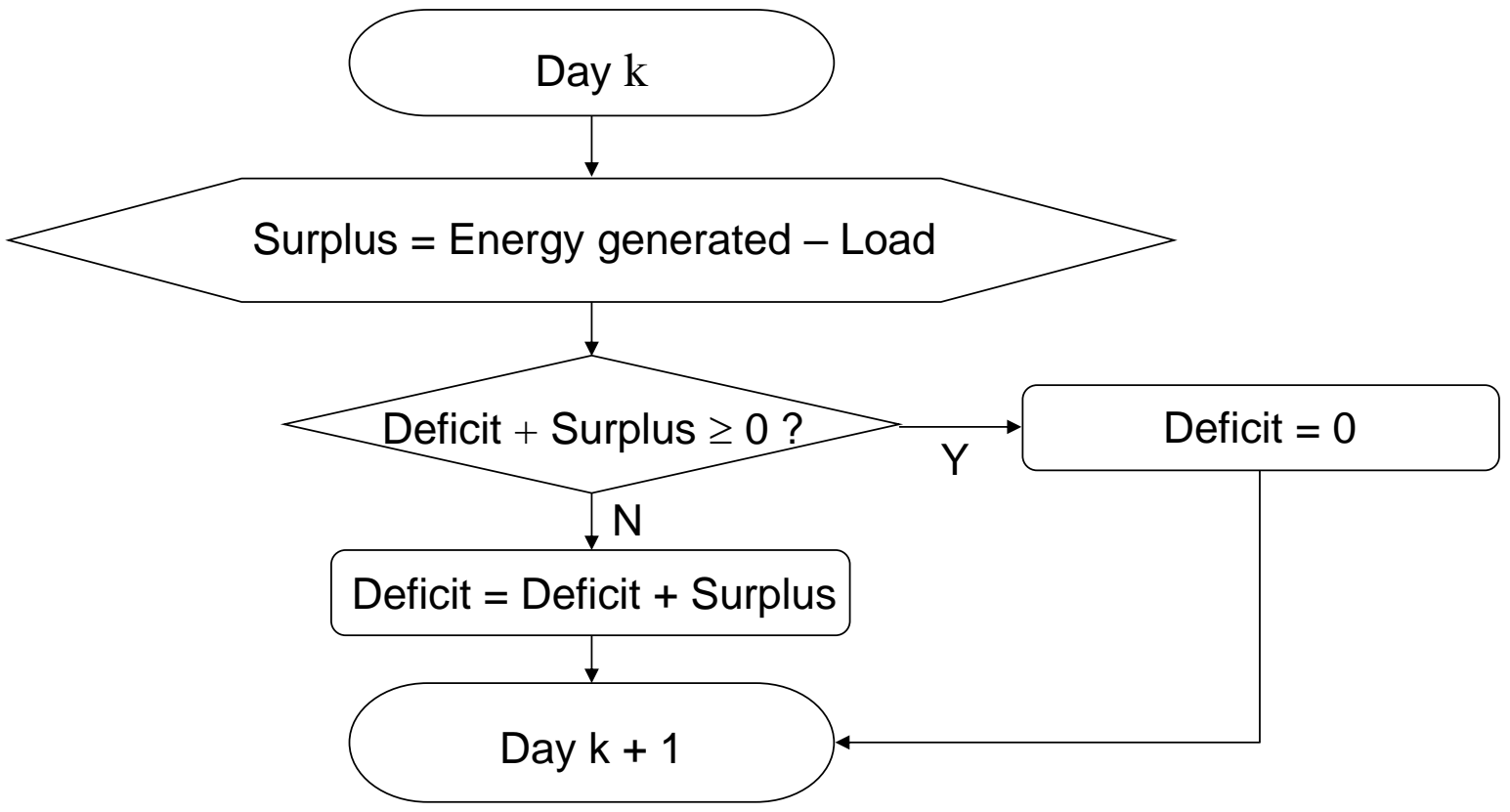

Fig. 4. A simplified flow chart, assuming a unit energy storage efficiency, used to determine the minimum storage capacity required for an uninterrupted power supply during the 30 year design period.

The flow chart in Fig. 4 assumes, for simplicity, that the energy storage efficiency is unity (a generalisation to more realistic values represents no fundamental difficulties and will be considered below). The model considers the difference between the energy generated and consumed during day $k$ (variable "surplus") which is either stored (if positive) or supplied from storage (if negative), and the net energy deficit in the storage (difference between the actual and maximum energy in the storage, negative or zero) is updated before moving onto day $(k+1)$. The size of the energy store needed if the system is to supply power without interruption now readily follows: it is equal to the magnitude of the maximum deficit during the design period. 
Let us consider, for illustration, the situation that the generation capacity is constrained to "minimum generation line". The energy deficit in the store as a function of time obtained using the algorithm in Fig. 4 which corresponds to several possible configurations with different solar and wind capacities is shown in Fig. 5a. The minimum storage size required for uninterrupted operation ranges from 277 days for purely photovoltaic generation and 170 days for a system based on wind, to the minimum storage requirement of 87 days for a system with $57 \%$ of electricity generated by wind and $43 \%$ by PV. We note that a large part of the storage requirement comes from the need to store energy over prolonged periods ranging over many years.

These large storage requirements can be reduced considerably by increasing the generation to remove the need for inter-annual storage of the generated energy. An example of such deficit profile when total generation exceeds load by $15 \%\left(f_{g}=1.15\right)$, is shown in Fig. 5b, reducing the required storage size to 40 days of load (approximately $34 \mathrm{TWh}$ ).

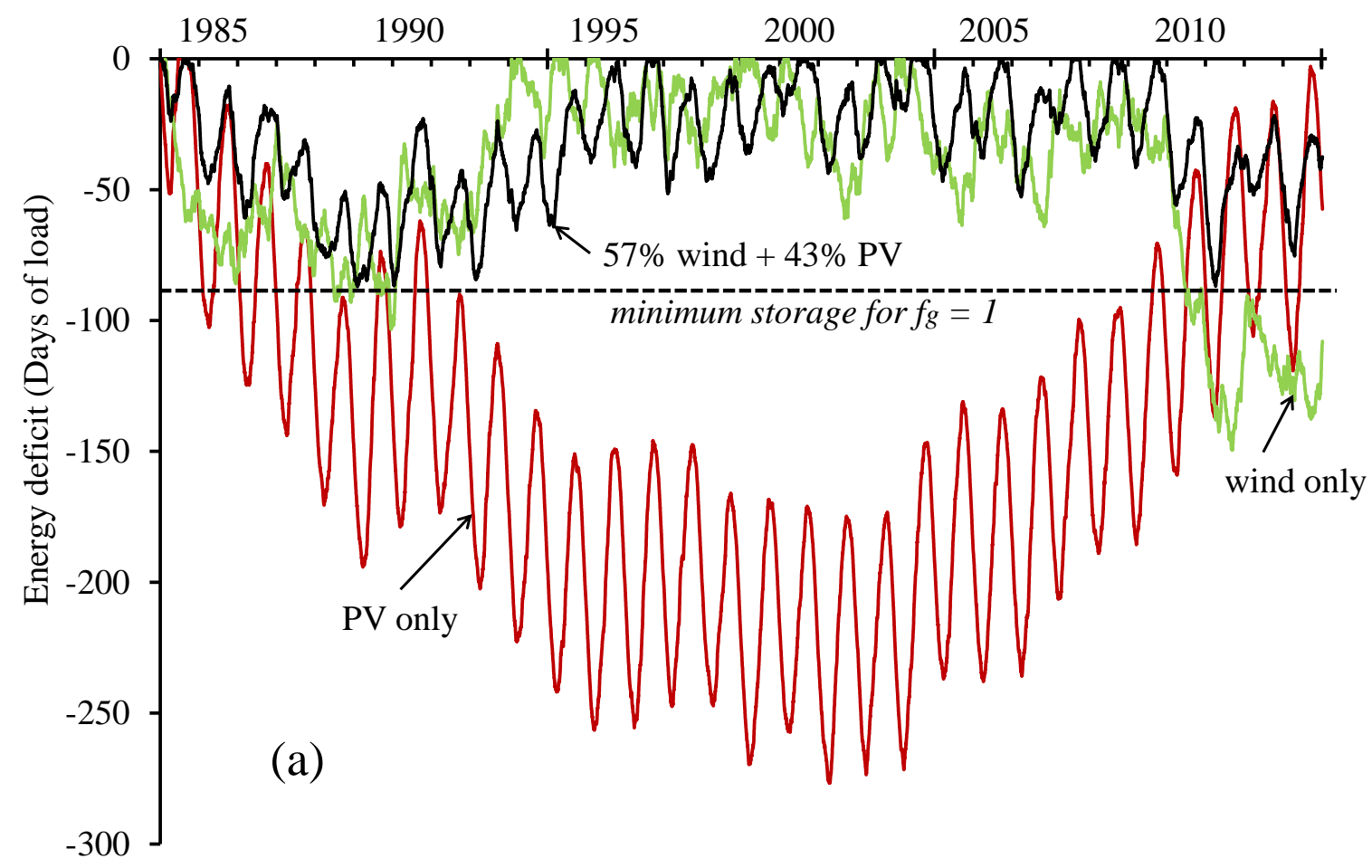




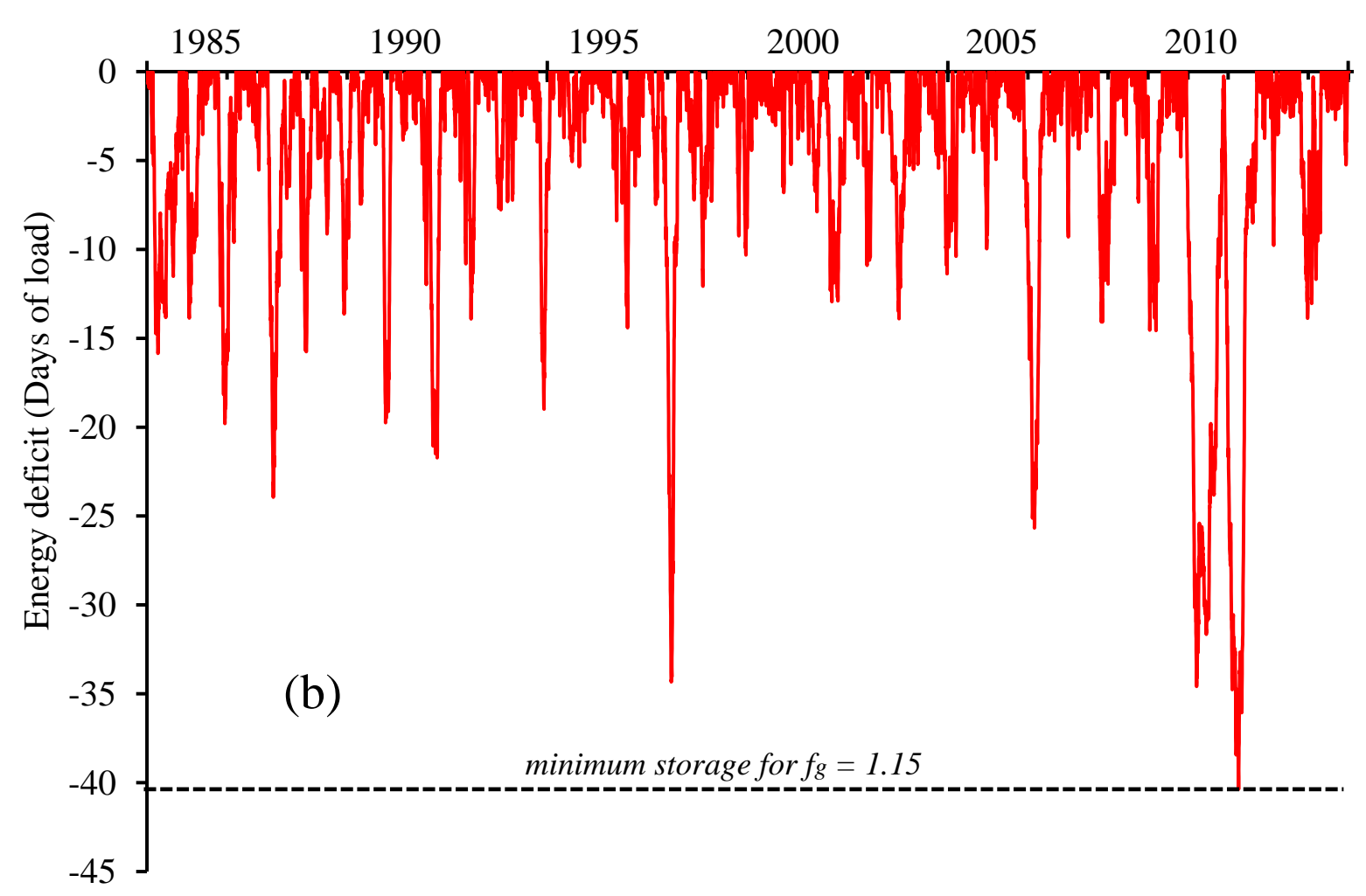

Fig. 5. The energy deficit as a function of time over the 30 year design period. (a) Three generation configurations on the "minimum generation line". Here, generation capacities $\overline{P_{w}}=2.04$ and $\overline{P_{s}}=$ 3.71 require the size of energy storage of 87 days;. (b) A system configuration with $\overline{P_{w}}=3.32$ and $\bar{P}_{S}=1.91$ which generates $15 \%$ more energy than consumed by the load reduces the required energy storage to 40 days of load (approximately $34 \mathrm{TWh}$ ).

This procedure can be used to determine the required energy storage size for any combination of wind and solar generation, with meaningful values obtained for system configurations above the minimum generation line. For a unit storage efficiency, these results are shown in Fig. 6, depicting both normalised and actual generation capacities. 


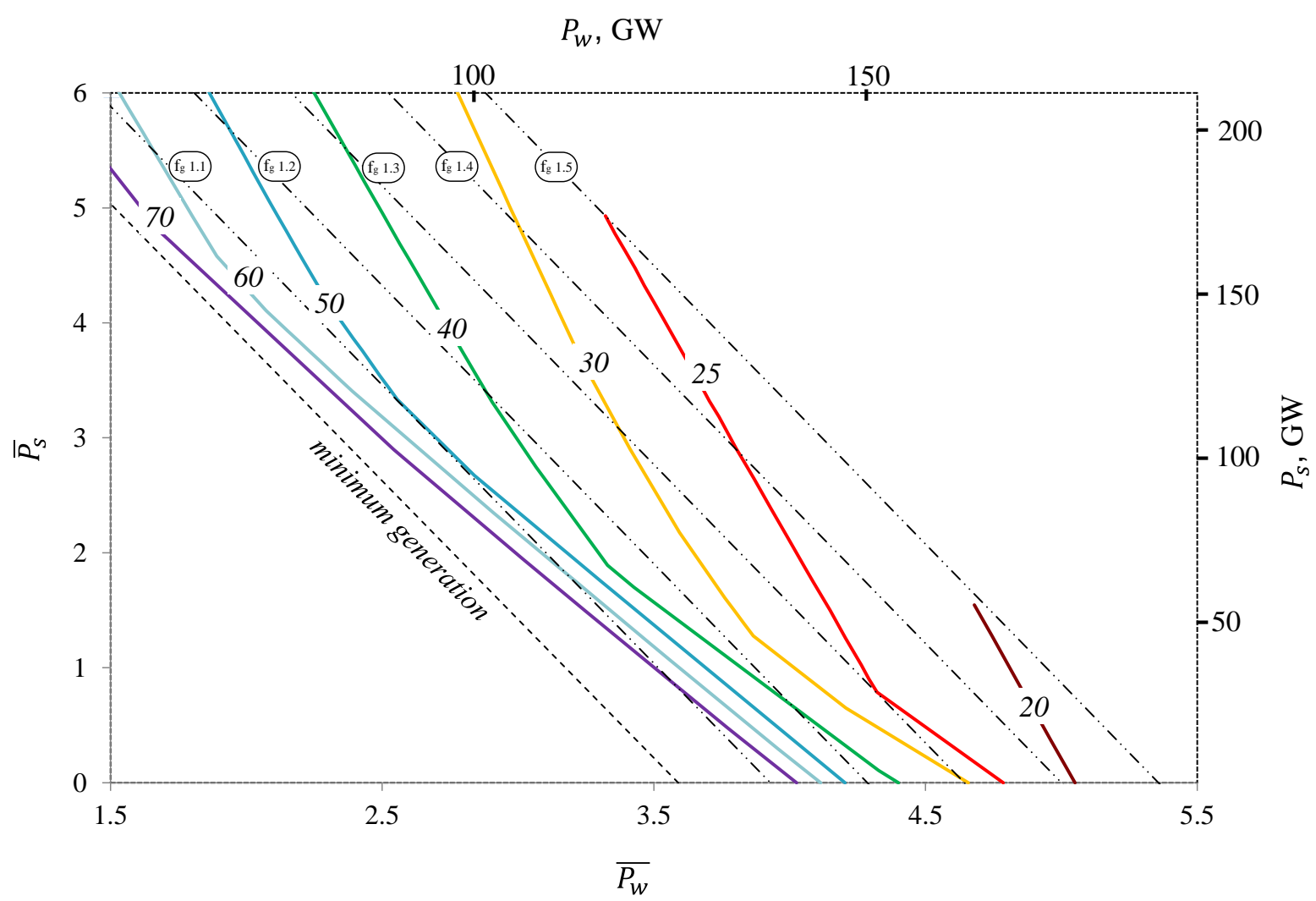

Fig. 6. The normalised generation capacities and storage requirements for a unit storage efficiency (full lines). Secondary axes show the actual generation capacities in GW. Dash-dot lines correspond to constant values of the total energy generation $f_{g}$ varying from the minimum generation $\left(f_{g}=1\right)$ up to $f_{g}=1.5$.

It is worth pausing briefly at this point to examine the broader significance of system configurations shown in Fig. 6. Increasing the combined generation capacity above the minimum needed to supply the load means that any excess energy - which cannot be accommodated by the storage - needs to be disposed of. Viewed in a different way, the output of the generators will have to be reduced below what they could otherwise produce given available resource - in other words, curtailed. In general, curtailment of wind and solar resources typically occurs ${ }^{19}$ because of existing transmission capacity (congestion) or lack of transmission access. It can also occur, in cases of excess generation during low load period, due to inability to reduce output from other generating sources if minimum generation thresholds have been reached, because of voltage or interconnection issues, or to maintain frequency requirements. In the present work we restrict our investigation to curtailments occurring solely because of potential excess in combined wind/solar production. Given that there is compensation to generators for curtailments, they are important parameters of the economic viability of the investments. Therefore, the suggested systems in this work are those that minimize the energy production and therefore the energy lost for constant storage size. This is in common with other studies on either fully or partly renewable electricity 
systems, which identify an optimum level of wind and PV mix, by looking at the minimum amount of the excess electricity production from renewable electricity. They do this either by a detailed system analysis, including technical and regulatory constraints ${ }^{20}$ by using computer models such as EnergyPLAN ${ }^{21}$, or by other methods ${ }^{22}$ which do not include such constrains.

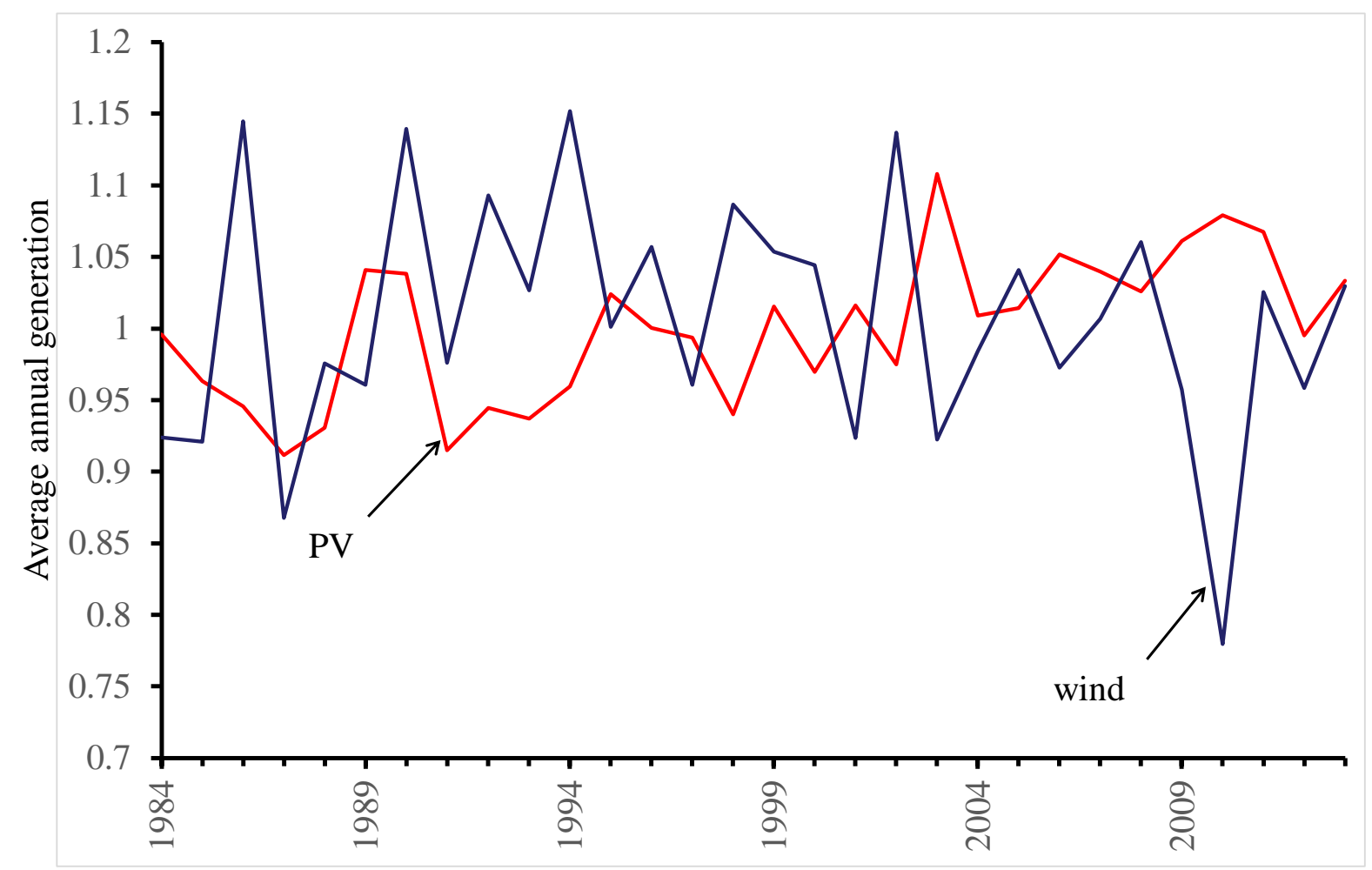

Figure 7 The average annual energy divided by the average load generated each year of the 30 year period by the wind and solar generators.

We may note that Fig. 5a shows a large deficit in the PV only configuration, due to a reduced PV production over prolonged periods of several years, between mid 1980s and late 1990s (see Fig. 7). A general decrease in surface solar radiation was observed at many sites during that period, a phenomenon often referred to as solar radiation dimming ${ }^{23,24}$ major contributors to which are considered to be increasing air pollution and associated aerosol loads. ${ }^{25}$

We should also note that minimum generation for a given storage does not necessarily mean smallest total generation capacity. It is not difficult to show (see Fig 6) that a system based solely on wind generation minimizes both storage size and generation capacity but it also means that more energy is curtailed (wasted), as indicated by the larger $f_{g}$. We will return to discuss this point further below. 
The methodology that we have developed assuming "perfect" energy storage is readily extended to a more realistic scenario when the storage efficiency is less than unity. The system model is again based on a simple energy balance between the energy $E(k)$ generated on day $k$, energy consumed as load $L(k)$, and energy stored or recovered from storage, as the case may be. Our model is independent of the storage technology; we only assume that energy is stored (storage "charging") with efficiency $\eta_{i n}$, and recovered from storage (storage "discharging") with efficiency $\eta_{\text {out }}$. The size (in energy units) of the energy storage will be denoted by $\Sigma$. If $S(k)$ is the amount of energy in the storage at the beginning of day $k$ we can now write, if $E(k) \geq L(k)$ (energy generated on day $k$ in excess of the load)

$$
S(k+1)=S(k)+\eta_{\text {in }}(E(k)-L(k))
$$

If, on the other hand, $E(k)<L(k)$,

$$
S(k+1)=S(k)+\frac{1}{\eta_{o u t}}(E(k)-L(k))
$$

If, on any day $k, S(k)>\Sigma$, we set $S(k)=\Sigma$ as the amount of energy stored cannot exceed $\Sigma$.

To determine the required size of energy storage for the GB power system to operate continuously without shedding load we subtract $\Sigma$ from both equations (3) and (4) and, denoting $Y(k)=S(k)-\Sigma$,

$$
Y(k+1)=Y(k)+\eta_{\text {in }}(E(k)-L(k))
$$

If, on the other hand, $E(k)<L(k)$,

$$
Y(k+1)=Y(k)+\frac{1}{\eta_{\text {out }}}(E(k)-L(k))
$$

$Y(k)$ (always negative or zero, on account of the finite size of the energy storage) represents the energy deficit in the storage and is the principal quantity of interest in this paper. We shall solve equations (5) and (6), subject to $Y(k) \leq 0$, to determine the minimum value $Y_{\min }$ of $Y(k)$ over the period of analysis. $\left|Y_{\min }\right|$ represents, for a particular size of the generation, the maximum amount of energy that needs to be retrieved from the storage to keep the system operational, and is therefore equal to the required size of the energy storage. In this work we will assume, for simplicity, that the two storage efficiencies are equal.

Clearly, storage efficiency less that unity introduces storage losses. It is then useful to distinguish between the excess energy generation that has to be curtailed, and that which is needed to provide for the inefficiency in charging and discharging the store. We define the storage loss relative to the load $b_{s}$ over the 30 -year design period by $b_{s}=$

$=\frac{\left(1-\boldsymbol{\eta}_{\text {in }}\right) \sum_{E(k)>L(k) ; Y(k+1)<0}\{\boldsymbol{E}(\boldsymbol{k})-\boldsymbol{L}(\boldsymbol{k})\}+\left(1-\frac{\mathbf{1}}{\boldsymbol{\eta}_{\text {in }}}\right) \sum_{Y(k+1)=0} \boldsymbol{Y}(\boldsymbol{k})+\left(\frac{\mathbf{1}}{\boldsymbol{\eta}_{\text {out }}}-1\right) \sum_{E(k)<L(k)}\{\boldsymbol{L}(\boldsymbol{k})-\boldsymbol{E}(\boldsymbol{k})\}}{L}$ 
where the first sum gives storage losses in charging, the third sum losses in discharging, and the second, a correction to charging losses when the store is nearly full and accepts only a part of the generated energy. We note, for future reference, that the third sum in (7) equals the amount of biomass that would be needed as an alternative to storage.

Since more energy now has to be spent to charge and discharge the store the need to curtail generation will be reduced in comparison with the ideal system (storage efficiency equal to unity). The generated energy that needs to be curtailed - in other words, the energy generated in excess of the load that cannot be accommodated as a result of a full store - can be defined relative to the load over the 30 year design period by

$$
c_{S}=\frac{\sum_{Y(k+1)=0}\left\{\frac{Y(k)}{\eta_{i n}}+(\boldsymbol{E}(\boldsymbol{k})-L(\boldsymbol{k})\}\right.}{L}
$$

Since we assume that the store is initially full, $f_{g}=1+b_{s}+c_{s}+y_{s}$, where $y_{s}$ is the energy remaining in the store at the end of the design period relative to total load.

Figure 9 shows the system configurations similar to those discussed in Fig. 6 but for a scenario with a roundtrip energy storage efficiency in a range between $75 \%$ and $85 \%$. This range was estimated for pumped storage ${ }^{26,27}$ which we consider to be the most appropriate in view of the substantial sizes involved.

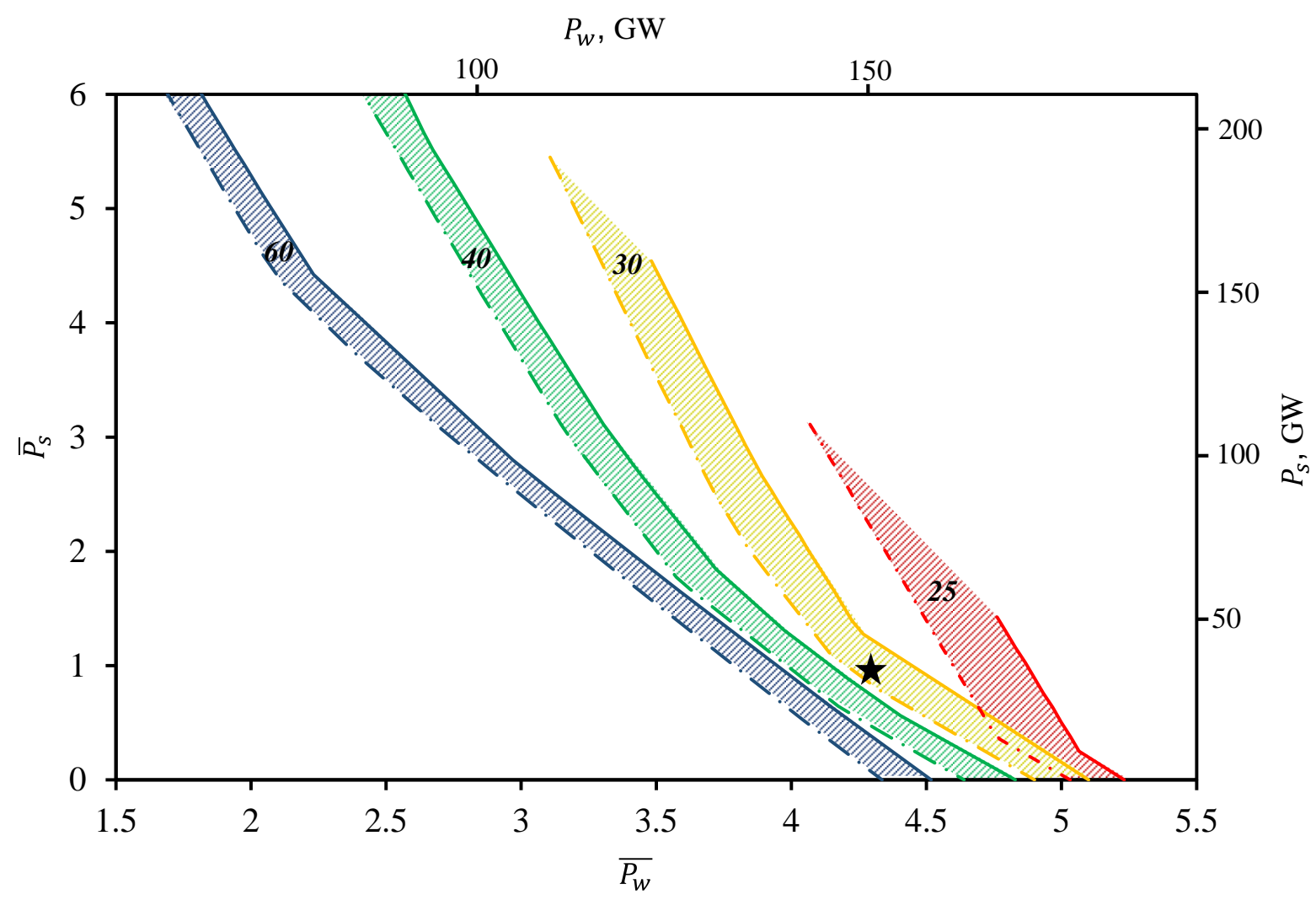

Fig. 9. The normalised generation capacities and storage requirements (shaded regions) for a storage efficiency between $75 \%$ (full lines) and $85 \%$ (dashed lines). Secondary axes show the actual generation capacities in GW. The asterisk denotes the model system discussed in the text. 
In a similar way to $100 \%$ storage efficiency, the storage requirement now drops sharply with the increase in wind capacity share, to approximately one month for a system dominated mainly by wind turbines.

It is worth illustrating our results on comparison with the actual GB power generation system. The average / model load used in this study (305TWh per year or $836 \mathrm{GWh}$ per day on average) as well as the profile are close to the actual 2013 electricity demand, supplied by a total capacity of about $82 \mathrm{GW}$, consisting principally of $20 \mathrm{GW}$ of coal, $34 \mathrm{GW}$ CCGT and $10 \mathrm{GW}$ of nuclear, but including also almost $11 \mathrm{GW}$ of wind and $3 \mathrm{GW}$ of $\mathrm{PV}^{28}$.

Systems that would supply this load without interruption are shown, for storage sizes between 25 and 60 days (approximately 21 and 50 TWh), in the shaded regions of Fig. 9. A specific choice of which system is optimal within this range can only come from economic considerations. Our paper focuses only on the engineering aspects; furthermore, the time frame for reaching capacities considered in this paper is, according to UK government proposals, some 30 years away. For the purposes of illustration, based on an economic scenario not too different from today (similar prices of wind and solar per $\mathrm{kW}$ and an intermediate size of energy storage) we can consider a system configuration with minimum total generation (depicted by an asterisk in Fig. 10) of about $150 \mathrm{GW}$ of wind and $35 \mathrm{GW}$ of $\mathrm{PV}$, with some 30 days ( $25 \mathrm{TWh}$ ) of storage. The energy deficit profile of such configuration is shown in Fig. 10. The curtailed energy is approximately $23 \%$ of the demand and the storage loss $7 \%$ of the demand.

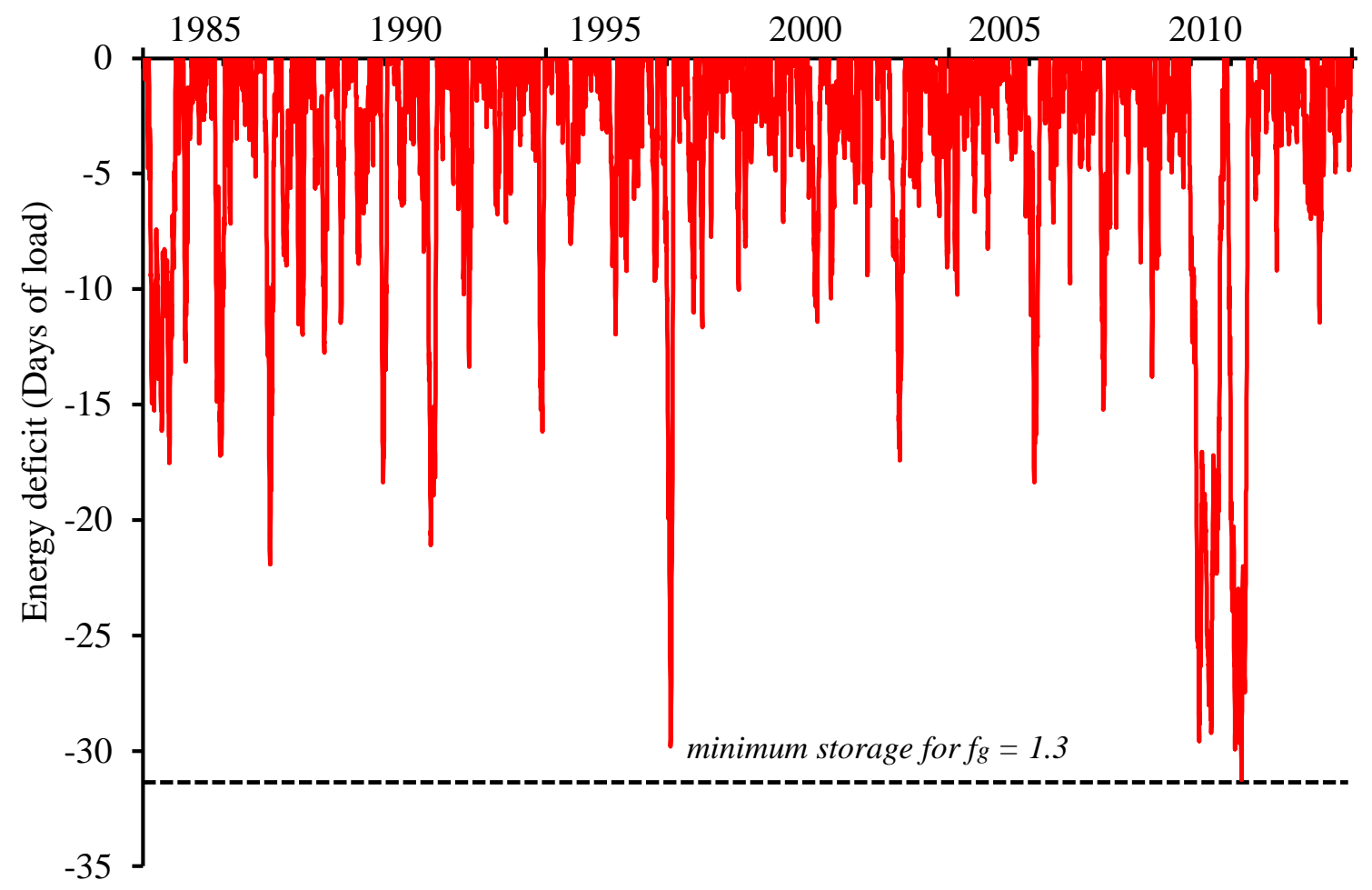

Fig. 10. The energy deficit as a function of time over the 30 year design period with the total energy generated increased by $30 \%$ from the minimum generation. System configuration with $146 \mathrm{GW}$ wind and $39 \mathrm{GW}$ solar requires energy storage 31 days of load (approximately $26 \mathrm{TWh}$ ) when the storage efficiency is $80 \%$ 
However, a firm energy supply could equally well be achieved with a smaller total generation capacity consisting of $170 \mathrm{GW}$ wind and $10 \mathrm{GW}$ solar and a smaller storage capacity of 25 days of load (approximately $21 \mathrm{TWh}$ ) but more energy needed to be curtailed (33\% of demand), and higher storage loss (8\% of demand) or a larger generation capacity consisting of $130 \mathrm{GW}$ wind and $60 \mathrm{GW}$ solar and larger storage capacity of 40 days of load (33.5 GWh) but less energy being curtailed (17\% of demand), and less storage loss ( $6 \%$ of demand). The reason that more energy is generated with less capacity (and vice versa) is due to a change in the generation mix that favours wind generation (and vice versa).

Energy storage that we considered in this paper to balance the power system can, of course, be replaced by burning (sustainable) fuel - for example, biomass, in a similar way as many countries currently use fossil fuel. The amount of fuel needed can easily be obtained by integrating the amount of energy taken out of the energy store, giving an average figure of 53 TWh per annum. This figure has to be supplemented by the energy needed to be supplied to compensate for the daily mismatch between generation and load. Unlike the "climate" deficit in the energy store considered above, this fuel has to be supplied in a cumulative manner, and the total amount will therefore be significantly greater that the $53 \mathrm{TWh}$ to cover the long term weather effects.

The amount of energy exchanged with the store which we have just discussed gives also an estimate how much energy would have to be traded with other systems in the absence of storage. The annual deficit (indicating import) of 53 TWh corresponds to average daily import of $146 \mathrm{GWh}$ which again has to be added to the daily mismatch. This can be compared with the average annual excess generation of $147 \mathrm{TWh}$ (403 GWh per day, on average) which would be exported.

Energy storage by electric cars is sometimes suggested as a useful means to balance the power system with a large penetration of intermittent generation. To estimate the potential of this approach, the storage size that may be available has been calculated using a simple model and the assumptions typically used in recent research ${ }^{22}$. The number of cars registered in GB in 2013 was approximately 29 millions $^{29}$. If all were equipped with a typical EV battery of 25 $\mathrm{kWh}$, with a round trip efficiency approaching $100 \%$, the storage potential would be approximately $726 \mathrm{GWh}$. This is less than one day of storage (0.87) and corresponds to only $7.6 \%$ of the deficit for 2013. Therefore, EV batteries could only usefully contribute to short term energy storage.

The model is easily generalised to a situation where a fraction of demand is supplied by nuclear / tidal (baseload) generation. A parametric study of the possible existence of a constant base load for 30 days of storage and unit storage efficiency is shown in Fig. 11. The size of a storage is now only fraction of the storage for $100 \%$ renewable generation. The shape of the curves, both in Fig. 9 and Fig. 11, indicates a minimum in the generated energy for the required storage which corresponds to the inflexion point of these curves. Therefore, these inflexion points on the storage contours define a minimum energy generation for a constant storage size. Interestingly, this minimum is always for a generation $f_{g}$ which approximately equals the renewable fraction multiplied by the constant $30 \%$. For example, if a constant baseload (for example, nuclear) supplies $50 \%$ of the total annual load, the total 
energy generated has to be increased by at least $0.5 * 30 \%=0.15$. The storage size is then the renewable fraction of energy generated, multiplied by the total load, in the present case, $0.5 * 30$ days of total load (12.5TWh). It should be noted that the inflection points move towards a mix of larger wind capacities with smaller solar capacities as the renewable fraction of energy generated increases.

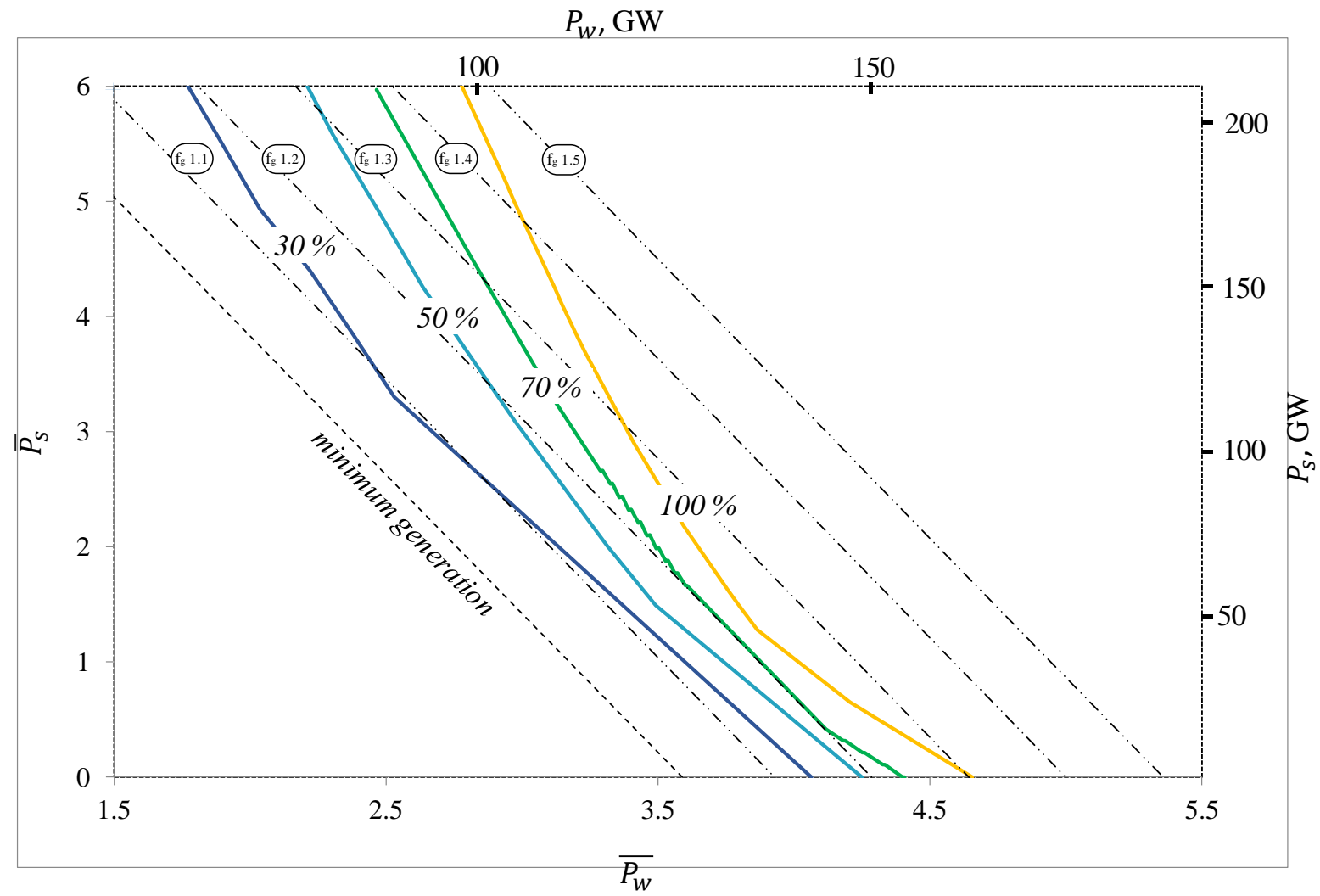

Figure 11 The normalized generation capacities for 30 days of storage when the renewable energy is a fraction of the total generated energy, for a unit storage efficiency (full lines). The primary and secondary axes show the normalised and actual generation capacities in GW. Dash-dot lines correspond to constant values of the total energy generation $f_{g}$, varying from the minimum generation $\left(f_{g}=1\right)$ up to $f_{g}=1.5$.

\section{Conclusion}

Using a system model based on energy balance between supply and demand, we have created framework which determines the possible configurations of a power system which supplies firm power but consists only of wind turbines, PV arrays and energy storage. Using the actual weather data between 1984 and 2013 and demand variation during the year (but normalised to a constant yearly total), we have determined the necessary size of energy store for the system to supply power without interruption over the 30 year design period. For a realistic storage efficiency between $75 \%$ and $85 \%$ our principal result can be summarised as a 30-30 rule: the current system based on dispatchable generation can be replaced by a hybrid wind/PV generation system producing approximately $30 \%$ more electrical energy than the 
demand, with some 30 days ( $25 \mathrm{TWh}$ ) of storage. In other words, in the presence of storage, the typical GB load (305 TWh total per year) could be supplied by about $150 \mathrm{GW}$ of wind turbines and $35 \mathrm{GW}$ of PV generation, with a similar reliability of supply. Our model also provides a methodology to consider other system configurations (summarised in the system configuration graph in Fig. 9), where a higher generation capacity is traded against a lower storage capacity, or vice versa.

In this paper we have focused attention on balancing the intermittent energy production solely by energy storage but the methodology also provides estimates of energy needed to balance the system by other means. Most often discussed is balancing the system by interconnections to other (continental) systems. Results obtained in this paper suggest that the compensation of seasonal or longer term weather effects would require the annual import of $53 \mathrm{TWh}$ of electricity, and the export (or curtailment) of $147 \mathrm{TWh}$, which should be added to the daily mismatch between generation and load (including "peak shaving").

Alternative potential strategies for balancing the system include the combustion of sustainable biomass. The above figure of 53 TWh of electricity needed to be supplied then translates to roughly 14 million tonnes of biomass per annum ${ }^{1}$.

It is often suggested is that the impact of intermittence can be reduced by implementing demand side management (DSM). Although effective in peak shaving and potentially reducing the need for storage during one day, our results show that DSM is unlikely to have much impact on the seasonal component of storage which is considered in this paper, unless load can be deferred on a time scale comparable with the charge-discharge cycles (weeks or even months, see Fig. 10).

This paper considers electricity storage as a "black box", without reference to a specific technology. To allow definite calculations to be carried out, the efficiency of chargedischarge cycle was based on currently accepted values for pumped hydro storage - chosen as the most likely option for the simple reason that this is currently the only technology operational at the required scale. The methodology, however, can be applied to other technologies - for example, electrochemical batteries which have seen rapid development during recent years. Notwithstanding, our results place restrictions on the feasibility of certain strategies that have been suggested - for example, the use of batteries in electric vehicles. A simple model (requirement of 30 million electric vehicles with a range of $500 \mathrm{~km}$ ), however, predicts the available storage capacity of several TWh (equivalent to one or two days of load) - in other words, a small fraction of what is needed to provide a firm capacity in the system.

We find that this 30-30 rule (30\% excess energy generated accompanied by 30 days of storage also applies approximately to scenarios where a fraction of the demand is supplied by a constant power source such as nuclear generation. We find the wind and solar generation capacities required for uninterrupted supply, for 30 days storage requirement and for several fractions of constant baseload, for the case of an ideal system (unit storage efficiency). Similar to the case of $100 \%$ renewable generation, a pure wind system minimizes the total

\footnotetext{
${ }^{1}$ Assuming conversion efficiency of $38 \%$ and a calorific value of $8 \mathrm{kWh} / \mathrm{kg}$.
} 
generation capacity but leads to more energy generated in excess of the load. There is again an optimum mix of solar and wind for which the total energy generated $\left(f_{g}\right)$ is minimized for each renewable fraction of energy generated. This optimum mix moves towards combinations of larger wind capacities with smaller solar capacities as the renewable fraction of energy generated increases.

\section{Acknowledgement}

Centre for Advanced Photovoltaics is supported by the Czech Ministry of Education, Youth and Sport. CZ.02.1.01/0.0/0.0/15_003/0000464.

\section{Data availability}

The solar radiation and wind speed data are accessible through Met Office (2012): Met Office Integrated Data Archive System (MIDAS) Land and Marine Surface Stations Data (1853current). NCAS British Atmospheric Data Centre, 10/04/2014. http://catalogue.ceda.ac.uk/uuid/220a65615218d5c9cc9e4785a3234bd0 (last visited 19/11/2017)

The electricity demand data have been obtained from the National Grid and, since 2005, are currently available from the National Grid website, http://www2.nationalgrid.com/UK/Industry-information/Electricity-transmission-operationaldata/Data-Explorer/ (last visited 19/11/2017). The rest of the data be available from the corresponding author on request.

\section{References}

\footnotetext{
${ }^{1}$ UK action following the Paris Agreement. Committee on Climate Change. October 2016

${ }^{2}$ Becker, S. et al. Features of a fully renewable US electricity system: Optimized mixes of wind and solar PV and transmission grid extensions. Energy 72, 443-458 (2014).

${ }^{3}$ Esteban, M., Zhang, Q., Utama, A., Tezuka, T. and Ishihara, K.N. Methodology to estimate the output of a dual solar-wind renewable energy system in Japan. Energy Policy 38, Issue 12, 7793-7802 (2010).

${ }^{4}$ Hong, S., Bradshaw, C.J.A. and Brook, B. W. Evaluating options for sustainable energy mixes in South Korea using scenario analysis. Energy 52, 237-244 (2013).

${ }^{5}$ Met Office (2012): Met Office Integrated Data Archive System (MIDAS) Land and Marine Surface Stations Data (1853-current). NCAS British Atmospheric Data Centre, 10/04/2014. http://catalogue.ceda.ac.uk/uuid/220a65615218d5c9cc9e4785a3234bd0 (last visited 19/11/2017)

${ }^{6}$ National Grid, Data explorer http://www2.nationalgrid.com/UK/Industryinformation/Electricity-transmission-operational-data/Data-Explorer/ (last visited 19/11/2017)

${ }^{7}$ Markvart, T. and Castañer, L. Practical Handbook of Photovoltaics. Fundamentals and Applications (Elsevier Science, 2011).
} 
${ }^{8}$ Study on UK offshore wind variability, (The Crown Estate Commissioners 2016), Garrant Hassan and Partners Ltd.

${ }^{9}$ Sinden, G. Characteristics of the UK wind resource: Long-term patterns and relationship to electricity demand. Energy Policy 35, 112-127 (2007). doi:10.1016/j.enpol.2005.10.003

${ }^{10}$ Watson, S. J., Kritharas, P., and Hodgson, G. J. Wind speed variability across the UK between 1957 and 2011. Wind Energy 18, 21-42 (2015). doi:10.1002/we.1679

${ }^{11}$ Nordex Wind Turbines, N90/2500, http //www.nordex-online.com/en/produkteservice/wind-turbines/n90-25-mw.html (last visited on 22/11/2016)

${ }^{12}$ Europe's Onshore and Offshore Wind Energy Potential, An assessment of environmental and economic constraints, European Environment Agency (EEA), Technical report, No 6/2009, ISSN 1725-2237.

${ }^{13}$ E. Hau, Wind Turbines. Fundamentals, Technologies, Application, Economics, $3^{\text {rd }}$ edition, Springer Verlag, Germany, 2013

${ }^{14}$ Burton, T. et al. Wind Energy Handbook (John Willey and Sons, 2011).

${ }^{15}$ National Statistics, Regional Renewable Statistics, Regional Statistics 2003-2015:

Unchanged Configuration Load Factors, (Department for Business, Energy \& Industrial

Strategy, Gov.UK, 2014) https://www.gov.uk/government/statistics/regional-renewablestatistics (last visited 20/11/2015)

${ }^{16}$ Ali, M., Matevosyan, J. and Milanovic, J.V. Probabilistic assessment of wind farm annual energy production. Electric Power Systems Research 89, 70- 79, (2012).

${ }^{17}$ EnergyPlus Engineering Reference, Version 8.7, DOE, (2017).

${ }^{18}$ Taylor J., Leloux J, Everard, A. M., Briggs J. and Buckley A. Monitoring thousands of distributed PV systems in the UK: Energy production and performance, PVSAT-11 (2015)

${ }^{19}$ Bird, L., Cochran, J., and Xi Wang, X., Wind and Solar Energy Curtailment: Experience and Practices in the United States, NREL, (2014).

${ }^{20}$ Lund $\mathrm{H}$. Large-scale integration of optimal combinations of PV, wind and wave power into the electricity supply. Renew Energy 2006, 31(4):503e15.

${ }^{21}$ H. Lund, "EnergyPLAN: Advanced Energy Systems Analysis Computer Model," Aalborg University, 2012.

${ }^{22}$ Andresen, G.B., Rodriguez, R.A., Becker, S., Greiner, M. The potential for arbitrage of wind and solar surplus power in Denmark, Energy, 76, 49-58, (2014).

${ }^{23}$ Wild, M., Global dimming and brightening: A review, Journal of Geophysical Research: Atmospheres, 114, Issue D10 (2009), doi:10.1029/2008JD011470.

${ }^{24}$ Müller,B., Wild,M., Driesse, A. and Behrens K. Rethinking solar resource assessments in the context of global dimming and brightening, Solar Energy, 99, 272-282 (2014).

${ }^{25}$ Stjern, C. W., Kristjansson, J. E. and Hansen A.W. Global dimming and global brightening: An analysis of surface radiation and cloud cover data in northern Europe, Int. J. Climatol., 29, 643 - 653 (2009), doi:10.1002/joc.1735.

${ }^{26}$ Technology Roadmap: Hydropower. (International Energy Agency, 2012)

${ }^{27}$ Norwegian hydropower for large-scale electricity balancing needs - Pilot study of technical, environmental and social challenges. (SINTEF Energy research, 2014); http://hdl.handle.net/11250/2384337

${ }^{28}$ Digest of United Kingdom Energy Statistics, 2014, Department of Energy and Climate Change

${ }^{29}$ Department for Transport statistics. Vehicle Licensing Statistics (https://www.gov.uk/government/collections/vehicles-statistics) Contributions

A.F. did the technical part of the work and contributed in writing. T.M. provided the initial version of the energy balance model, provided guidance throughout the work and wrote 
the final version of the manuscript. Both A.F. and T.M. discussed the results and the reviewed the manuscript. G.L. worked at the initial stage of development of the energy balance model.

\section{Competing interests}

The authors declare no competing financial interests. 